\title{
USER EXPERIENCE (UX) SEBAGAI BAGIAN \\ DARI PEMIKIRAN DESAIN DALAM PENDIDIKAN TINGGI DESAIN KOMUNIKASI VISUAL
}

\author{
Mendiola B. Wiryawan \\ Jurusan Desain Komunikasi Visual, School of Design, BINUS University \\ Jln. K.H. Syahdan No. 9, Palmerah, Jakarta Barat 11480 \\ mendiola@binus.ac.id
}

\begin{abstract}
Digital world, internet and mobile have made communication does not move in one way anymore. Visual Communication as a part of Communication recently is going to be more personal, segmented, interactive, user-generated content, accessible and available in huge quantities. In the positive side, users have more options to receive or to respond communication signals according to his/her needs and wants. In opposite, now everybody gets information clutter caused by unbalanced information between what we can received and what we can digested. For that reason we need method to study the people as an object of our communication. Learning user experience concept make us understand more about our object insight. The aim of this paper is to review principles that used in UX study. In the future we expect this discourse will be assesed and used in a design thinking method and developed in visual communication design institution. Research method used in this paper is based on literatural studies. Understanding of UX will help designers developing design that can be effectively communicate with their segement.
\end{abstract}

Keywords: user experience, design

\begin{abstract}
ABSTRAK
Dunia digital, internet, dan mobile telah menciptakan komunikasi tidak lagi satu arah. Komunikasi visual sebagai salah satu bagian dari ilmu komunikasi saat ini telah semakin menjadi komunikasi yang personal, tersegmentasi, interaktif, user generated content, mudah diakses, dan tersedia dalam berbagai pilihan melimpah. Akibat positifnya adalah pengguna (user) mempunyai keragaman pilihan untuk menerima sinyal komunikasi apapun dan meresponnya yang sesuai dengan pilihannya. Negatifnya, saat ini terjadi kekacauan informasi sebagai akibat dari banyaknya informasi yang didapat tidak sebanding dengan informasi yang dapat dicerna. Untuk itu diperlukan sebuah metode dalam mempelajari bagaimana sebuah desain dapat berkomunikasi dengan khalaknya. Salah satu cara mempelajarinya adalah dengan mempelajari user experience (UX). Tujuan tulisan ini adalah untuk meninjau prinsip-prisip yang dipakai dalam studi UX. Diharapkan tulisan ini menjadi wacana awal bagaimana UX dikaji dan di manfaatkan dalam institusi pendidikan tinggi Desain Komunikasi Visual (DKV), terutama dalam mendesain dalam media digital yang semakin berkembang. Metodologi yang dipakai dalam penelitian jurnal ini adalah studi literatur yang diterbitkan mengenai UX. Pemahaman terhadap UX akan membantu seorang desainer dalam merancang desain yang dapat diterima khalayaknya dengan baik.
\end{abstract}

Kata kunci: user experience, desain 


\section{PENDAHULUAN}

Dunia digital, internet, dan mobile telah membawa perubahan besar dalam dua dekade ini. Perkembangan digital telah mengubah proses dan metode dari dunia analogi yang sebelumnya telah ada menjadi lebih cepat dan lebih efisien. Dunia internet sebagai infrastruktur memungkinkan dunia digital terhubung antar tempat yang satu dengan tempat lainnya. Akibatnya, informasi dapat dipindahkan dari tempat satu ke tempat lain dalam waktu yang singkat. Akhirnya teknologi mobile menguatkan penggunaan dunia digital menjadi produk yg demokratis, terjangkau dan dapat dinikmati orang banyak, dan dapat memenuhi kebutuhan sehari-hari.

Dunia digital memungkinkan para desainer komunikasi visual meninggalkan alat typesetter manual, pekerjaan paste up, dan mengurangi tingkat kemampuan yang dibutuhkan dalam membuat final artwork. Dunia internet memungkinkan desain komunikasi visual dapat dikomunikasikan dari tempat satu ke tempat lainnya dengan cepat, dan dunia mobile membuat desain dapat dikonsumsi orang banyak dengan lebih personal dan tersegmentasi. Dengan teknologi internet dan mobile, dunia audio visual semakin menjadi realita yang tidak dapat terpisahkan dengan kehidupan kita. Jika dahulu kita cukup puas dengan layar ponsel hitam putih, statis dan pixelate; sekarang kita dimanjakan dengan perangkat mobile dengan animasi, piksel yg begitu halus, desain grafis yang hyper-realism, lengkap dengan kemudahan untuk berinteraksi dengannya.

Hadirnya teknologi tentunya selalu membawa keuntungan baik kerugian. Teknologi digital melengkapi kita dengan Artificial Intelligent (AI) yang membuat seorang desainer komunikasi visual lebih dimudahkan dalam membuat sebuah desain. Jika dahulu seorang desainer memerlukan ketelitian dan keahlian dalam menggambar, menata, dan menyelesaikan sebuah desain, saat ini sedikit banyak akan dibantu oleh teknologi AI tadi yang membuat proses desain menjadi lebih mudah, cepat dan efisien. Di sisi lain, karena kemudahan akses dalam membuat sebuah desain, banyak sekali desainer lahir baik dari institusi formal maupun nonformal. Akibatnya persaingan yang ketat menjadi tak terelakan, yang terbaik dalam kemampuan, pengelolaan brand dan komunikasi, dan memiliki peruntungan yang baik akan bertahan dan memenangkan persaingan.

Dari sisi kemampuan dan pemikiran, desainer yang baik tidak boleh saja hanya memikirkan teknologi dan eksekusi artistik visual. Perlu pemahaman lebih lanjut terhadap proses bagaimana sebuah desain menjadi integrated dalam keseharian pemakainya. Sebagai institusi pendidikan yang mengusung teknologi sebagai basis pemikiran, BINUS University harus membekali peserta didiknya tentang hal ini. Selain memberikan pengetahuan tentang teknologi piranti lunak terbaru bagi peserta didiknya, program S1 BINUS seyogyanya memberikan juga pemikiran dan pemahaman yang mendasar tentang apa yang terjadi dari subyek teknologi itu sendiri yaitu manusia. Inilah mengapa pengetahuan tentang user experience sangat diperlukan sebagai landasan sukses tidaknya sebuah desain di dalam sebuah masyarakat, apalagi desain yang menggunakan media digital seperti yang berkembang saat ini.

\section{User Experience}

Menurut definisi dari ISO 9241-210, user experience adalah persepsi seseorang dan responnya dari penggunaan sebuah produk, sistem, atau jasa. User Experiece (UX) menilai seberapa kepuasan dan kenyamanan seseorang terhadap sebuah produk, sistem, dan jasa. Sebuah prinsip dalam membangun UX adalah khalayak mempunyai kekuasaan dalam menentukan tingkat kepuasan sendiri (costumer rule). Seberapa pun bagusnya fitur sebuah produk, sistem, atau jasa, tanpa khalayak yang dituju dapat merasakan kepuasan, kaidah, dan kenyamanan dalam berinteraksi maka tingkat UX menjadi rendah. Perkembangan dunia digital dan mobile menjadikan UX menjadi lebih complicated dan multidimensi. Kiniseseorang dapat mengakses sebuah situs web dari berbagai piranti. 
Perancangan UX pun mengalami ekspansi, karena pengalaman dalam sebuah piranti akan berbeda dengan piranti lainnya. Mengakses web dari komputer desktop akan berbeda dengan mengakses web yang sama lewat smart phone. Begitu juga media digital yang ditampilan semakin beragam dengan hadirnya social media. Namun dalam hal content delivery sebuah brand harus mengeluarkan satu bahasa yang sama di berbagai channel dan media. Untuk itu konsep UX perlu dipelajari lebih lanjut agar komunikasi brand tetap solid dan fokus.

Untuk mengerti konsep UX kita akan meninjau dua model yang dibuat tentang hal ini, yaitu model Jesse James Garett dan David Armano.

\section{Model Jesse James Garett}

Jesse James Garrett dalam bukunya The Elements of User Experience: User-Centered Design for the Web. menciptakan sebuah model untuk menjelaskan Elemen dari User Experience.

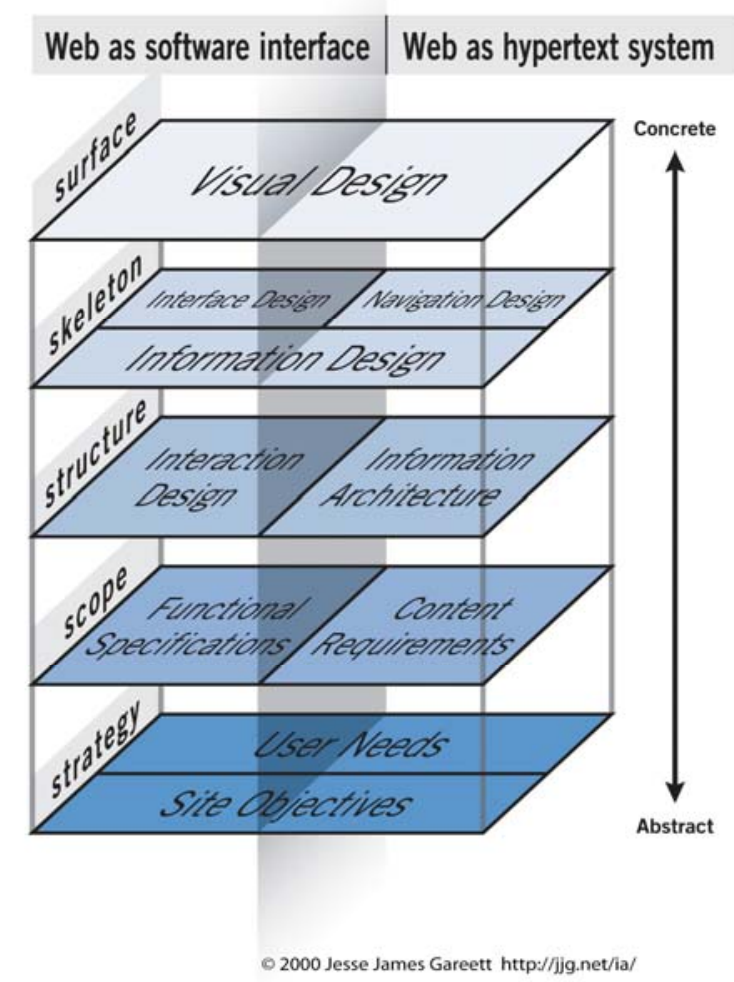

Gambar 1 Model Jesse James Garrett untuk Elemen User Experience

Garrett membagi diagramnya menjadi 5 proses yaitu: bidang strategi, bidang lingkup, bidang struktur, bidang rangka, dan bidang permukaan. Bidang strategi (strategic plane) menjadi platform dari pembentukan cetak biru experience. Disini dirumuskan semua objektif yang ingin dicapai dari proses pembentukan experience, baik dari sisi kebutuhan pengguna maupun produsen komunikasi.

Tahap bidang lingkup dipertanyakan apa yang menjadi batasan dalam penciptaan pengalaman bagi pengguna. Di bidang ini Garrett membagi menjadi dua sisi yaitu: sisi software interface (konten) dan hypertext system (konteks). Di sisi konteks, sistematika fungsional harus dipertimbangkan. Sedangkan di sisi konten, kebutuhan-kebutuhan informasi harus pula telah dipertimbangkan secara matang. Batasan Lingkup juga harus datang dari berbagai departmen terkait seperti departemen marketing, sales, supply chain, IT, dan sebagainya. Sebagai contoh: Sebuah perusahaan ingin menjual 
beberapa produk memerlukan beberapa informasi seperti: deskripsi produk, alasan pembelian produk, benefit produk, shopping cartuntuk pembelian e commerce, metode pembayaran, dan sebagainya. Dalam setiap lingkup diperlukan kebutuhan (requirement) tertentu, misalnya: pada lingkup kategori produk, diperlukan spesifikasi produk, foto produk, warna produk, dan sebagainya.

Tahap bisang struktur (struktur plane) adalah tahap pembuatan struktur informasi agar komunikasi berjalan sesuai dengan urutan yang diharapkan. Tahap ini dapat disebut juga sebagai tahap pembuatan arsitektur informasi. Hal yang perlu diperhatikan dalam pembentukan struktur informasi adalah harus mengacu pada kemudahan pelanggan dalam mengakses informasi. Untuk menggambarkan struktur informasi dapat disajikan dalam flowchart. Dalam tahap ini interaksi dengan pengguna juga harus ditentukan. Misalnya bagaimana pengguna berpindah dari informasi satu ke informasi lainnya dengan mudah tanpa menjadi bingung.

Tahap bidang rangka (skeleton plane) ibarat pembuatan draft layout dimana struktur informasi telah diaplikasikan ke dalam layout namun belum dalam tampilan visual akhir. Dalam dunia desain komunikasi visual tahap ini adalah pembuatan grid lay out dan penempatan teks di dalamnya. Ketepatan dalam meletakan informasi pada media komunikasi menjadi dasar mudah tidaknya hirarki informasi dapat disampaikan.

Tahap bidang permukaan (surface plane) diibaratkan polesan terakhir yang memberi tone and manner tampilan visual. Disini dipertimbangkan elemen dan prinsip desain seperti gerak, warna, harmoni, dan sebagainya.

Model Garrett merupakan model linear dimana proses satu harus dimulai jika proses sebelumnya telah selesai.

\section{Model David Armano}

David Armano, seorang Executive Vice President Global Innovation \& Integration di Edelman Digital, sebuah agensi digital terkemuka mengemukakan sebuah model interactive experience. Jika model Garrett lebih mengaris bawahi struktur, interaksi, dan kegunaan (usability), model Armano menarik ke belakang beberapa langkah dalam mencari user insight. Armano membagi prosesnya menjadi 5 langkah yaitu uncover, define, ideate, build, dan desain.

Uncover adalah pencarian sesuatu yang mendasar dari motivasi dan kepentingan customer, business, brand, yang dihubungkan dengan pemahaman wawasan teknologi. Dalam mencari customer insightdapat digunakan berbagai perangkat riset seperti behaviour mapping, social trends analysis, dan sebagainya, untuk mencari model rasional dan emosional khalayak yang dituju.

Tahap define ini merupakan tahapan perumusan strategi pembentukan pengalaman khalayak. Tahap ini mirip dengan tahap strategy plane pada model Garrett. Tujuan dari tahap ini adalah memberikan inspirasi dan arah baik kepada internal team maupun klien.

Ideate merupakan tahap kolaborasi dan eksplorasi. Dalam dunia pendidikan kreatifitas, sering juga disebut proses emphatising yaitu proses memahami khalayak dengan memasuki dunia mereka dan berperan sebagai mereka. Kemudian dicari pendekatan yang paling tepat untuk khalayak sesuai tujuan komunikasi. Build adalah proses membuat Big Ideadan mencoba mewujudkannya lewat prototype. Prototype diuji dan diperbaiki lewat riset kepada khalayak. Proses desain adalah proses finalisasi dan eksekusi dari prototype yang telah diuji. Semua fungsi dan interaksi dimaksimalkan di proses ini. 


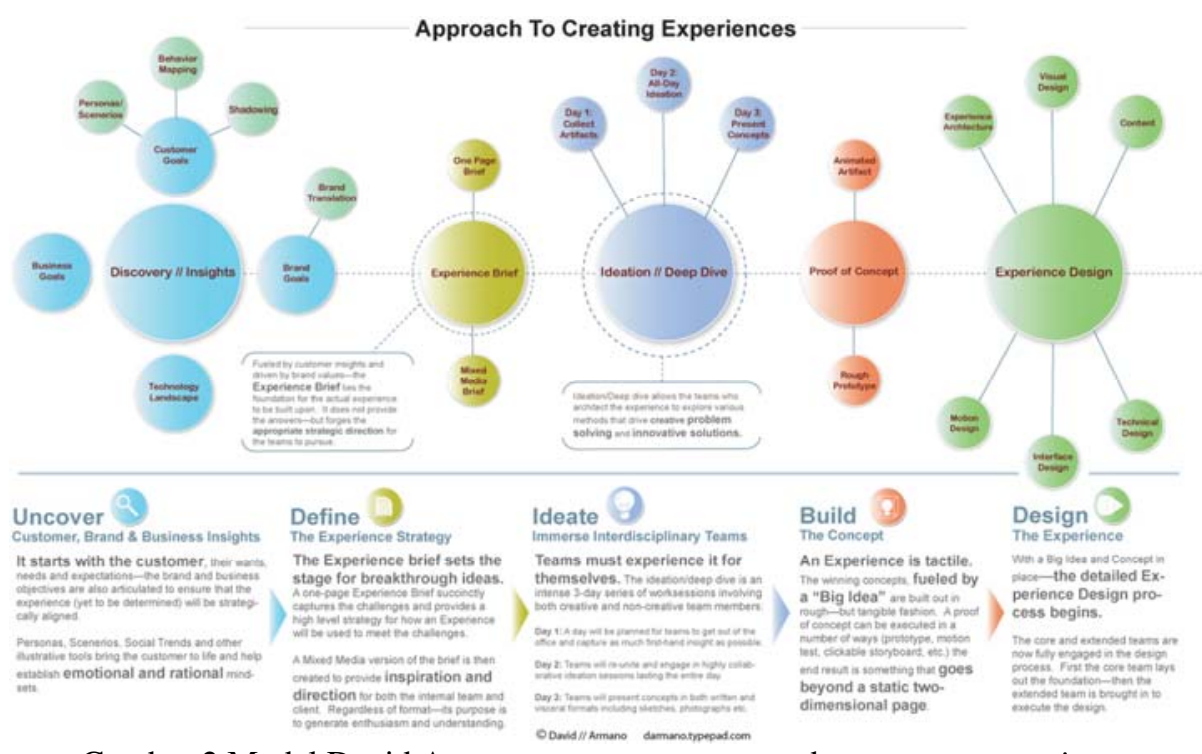

Gambar 2 Model David Armano tentang proses pembuatan user experience

\section{Usability sebagai Konsep Dasar User Experience}

Konsep kebergunaan (usability) merupakan konsep dasar dari user experience.Konsep UX diuji oleh penggunanya berdasarkan asas kebergunaan ini. Sering kali konsep usability disandingkan dengan kata user friendly dan istilah-istilah lain seperti computer-human interaction (CHI), human computer interaction (HCI), user-centered design (UCD), man-machine interface (MMI), humanmachine interface (HMI), operator machine interface (OMI), user interface design (UID), human factors (HF) dan ergonomis. Usability dan utility membentuk usefullness (Grundin, 1992). Sementara usability mempertanyakan seberapa baik pengguna menggunakan sebuah fungsi, utility mempertanyakan apakah sebuah fungsi tetap dalam prinsip-prinsipnya. Usability mengaplikasikan semua aspek sistematika dari interaksi manusia termasuk didalamnya prosedur instalasi dan prosedur perawatan (maintenance).

Menurut Nielsen (1993), usability mempunyai beberapa komponen, yaitu learnability, efficiency, memorability, errors, dan satisfaction. Learnability adalah sistem yang dibuat haruslah mudah untuk dipelajari supaya pengguna dapat dengan cepat bekerja dengan sistem yang ada. Learnability dinilai berdasarkan tingkat profisiensi berbanding dengan waktu dan dapat dicatat dalam bentuk kurva pembelajaran (learning curve).

Efficiency yaitu berarti bahwa sebuah sistem harus efisien untuk digunakan sehingga nilai produktifitas yang tinggi dimungkinkan. Memorability yaitu berarti bahwa sebuah sistem haruslah mudah diingat (atau mampu mengingatkan), sehingga seorang pengguna biasa bisa kembali menggunakan setelah beberapa periode waktu tanpa harus mempelajarinya kembali semuanya dari awal. Errors berarti bahwa sebuah sistem harus mempunyai tingkat kesalahan yang kecil sehingga pengguna membuat kesalahan sekecil mungkin dan jika seseorang melakukan kesalahan, dapat segera memperbaikinya atau kembali ke langkah sebelumnya. Satisfaction yaitu bahwa sebuah sistem harus menyenangkan untuk digunakan sehingga pengguna secara subyektif merasa senang atau nyaman.

Lima komponen tersebut dapat juga dipakai dalam prinsip usability dalam desain komunikasi visual, misalnya learnability dalam desain komunikasi visual menyangkut: (1) bagaimana sebuah komunikasi simbol dapat dimengerti dengan cepat dan tepat (misalnya pada icon). Prisip-prinsip seperti gestalt, legibility, readibility, culture refference, accesibility, semiotik, menjadi referensi yang 
baik dalam menciptakan proses learnability; (2) prinsip keterhubungan sebuah sistem visual yang satu dengan lainnya. Prinsip visual sequence, yaitu bagaimana sebuah visual menjadi sebuah rangkaian komunikasi dalam dimensi ruang atau waktu harus benar-benar dipertimbangkan dan dipelajari dengan seksama; (3) prinsip referensi atau pengalaman pengguna di waktu sebelumnya menjadi salah satu penentu keberhasilan dan kecepatan dalam kurva pembelajaran; dan (4) prinsip limitasi dari ruang, waktu, dan keterbatasan fisik lainnya dari pengguna dan keadaan sekitarnya harus dipelajari dengan seksama. Misalnya apakah pengguna orang yang pertama kali menggunakan device ataukah orang yang sudah terbiasa menggunakan device.

Prinsip efisiensi pada pengguna mungkin tidak berlaku untuk desainer komunikasi visual yang bekerja dengan media cetak konvensional ataupun dengan media tanpa interaktivitas. Konsep ini berlaku sejak desain komunikasi visual dilibatkan di dalam media interaktif. Sejauh mana efisiensi adalah perbandingan upaya dibandingkan dengan penggunaan waktu. Tingkat efisiensi ini melibatkan manajemen navigasi. Elemen visual yang baik akan mendukung tingkat efisiensi pengguna dalam menggunakan web.

Prinsip memorability memang berlaku di semua media desain komunikasi visual. Di dalamnya terkadung prinsip: Kebaruan, Keberbedaan, dan Relevansi sebuah pengalaman visual bagi khalayak yang dituju. Desainer yang baik mampu memasukan kualitas estetika dan faktor wow di dalam konsep ini.

Kesalahan sering terjadi seiring dengan aktivitas yang dilakukan manusia. Demikian juga di dalam interaktifitas. Ada 2 macam jenis kesalahan, yaitu slip dan mistakes. Slip berarti kesalahan yang sifatnya tindakan atau kesalahan eksekusi. Kesalahan ini diakibatkan karena ketidaksadaran perilaku, kebiasaan yang diubah, atau akibat interupsi tindakan. Misalnya seseorang salah menekan tombol keluar, padahal masih dalam tahap pengerjaan. Dalam merancang interaktifitas, kesalahan ini dapat dicegah dengan adanya sistem konfirmasi, dan limitasi konstrain agar kesalahan tidak terjadi. Contoh konfirmasi adalah pop up window yang menanyakan apakah kita akan keluar aplikasi tanpa menyimpan terlebih dahulu dan contoh konstrain adalah bentuk tombol yang hanya daat digerakan ke arah tertentu agar kita tidak dapat secara tidak sengaja mengubahnya. Mistakes berarti kesalahan yang sifatnya kesalahan tujuan atau salah perencanaan. Kesalahan ini bisa dikarenakan: persepsi yang salah, keputusan yang salah, atau pengetahuan yang salah. Desain komunikasi visual yang baik dapat meminimalisasi kesalahan dengan memberi arahan dan penjelasan, kesadaran atas tahapan, serta peringatan tertentu. Kesalahan dapat dipelajari melalui riset, dan harus diantisipasi sedini mungkin untuk mendukung UX secara baik.

Prinsip kepuasan (satisfaction) pengguna merupakan prinsip yang sangat subyektif. Pengukuran tingkat kepuasan mempunyai dimensi yang berbeda beda. Seringkali riset tentang kepuasan khalayak tidak akurat, karena apa yang diucapkan khalayak tidak menggambarkan kondisi mental sebenarnya. Saat ini penelitian yang melibatkan psikologis dalam hubungannya dengan fisiologis seperti electroencephalograms (EEGs), penelitian pelebaran pupil, detak jantung, konduktivitas kulit, tekanan darah, dan level dari adrenalin dalam darah telah dipakai dalam menganalisa tingkat kenyamanan dan stress khalayak (Mullins \& Treu 1991; Schleifer, 1990; Wastell, 1990).

Keilmuan seperti neuroscience juga dilibatkan dalam menilai hubungan khalayak terhadap stimulus desain visual (Lindstorm, 2008).Dalam wilayah estetika, tingkat kepuasan visual dipengaruhi juga oleh trend, budaya, fisiologis dan psikologis khalayak tertentu. 


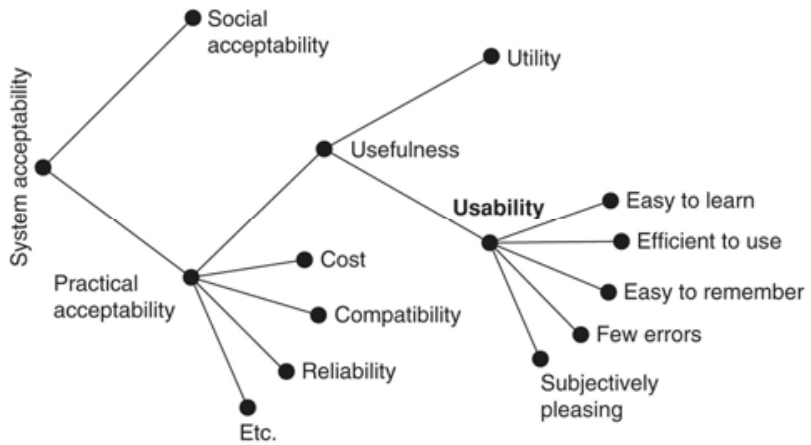

Gambar 3 Model Jacob Nielsen untuk atribut dari sistem acceptibility

\section{Information Architecture Design}

Mendesain arsitektur informasi diperlukan sebagai bagian dari proses perancanganUX. Definisi arsitektur informasi (Rosenfeld \& Morville, 2006) adalah: (1) kombinasi organisasi, sistem pelabelan, skemanavigasi danmekanisme pengambilan keputusan dalam suatu ruang informasi; (2) desain struktural dari ruang informasi untuk memfasilitasi penyelesaian tugas dan akses intuitif konten; (3) paduan kesenian dan keilmuan dalam membentuk informasi produk dan pengalaman yang mendukung kegunaan dan kemudah penemuan; (4) sebuah kemunculan disiplin dan komunitas praktis yang memfokuskan pada prinsip desain dan arsitektur.

Menurut Rosenfeld \& Morville (2006) ada empat hal representasi dari informasi arsitektur di dalam sebuah situs web: pencarian, sistem organisasi, sistem labelisasi, dan sistem navigasi. Rosenfeld \& Morville membagi 4 pendekatan dari pencarian di dalam internet: (1) pencarian seksama (ketika pengunjung mencari segalanya berkaitan dengan subjek tertentu atau istilah); (2) pencarian eksplorasi (ketika mereka sedang mencari hanya beberapa hal); (3) menemukan hal yang tepat (ketika mereka sedang mencari hal yang telah ditentukan spesifikasinya); (4) pencarian kembali (ketika mereka sedang mencari untuk sesuatu yang mereka telah temukan sebelumnya).

Desain komunikasi yang baik harus mempermudah pencarian. Desain harus mengantisipasi pencarian sesuai dengan kebutuhan dan keinginan target yang dituju. Antisipasi bisa berupa tawaran pencarian dan saran pencarian. Komunikasi tentang tawaran pencarian dan saran pencarian pun harus dibuat komunikatif, menarik, dan muncul di saat yang tepat.

Sistem organisasi adalah cara pengelompokan informasi berdasarkan kategori tertentu. Pengkategorian dapat dalam bentuk: alfabetikal, kronologis, satuan pengukuran (misal harga tertentu, besaran tertentu), tema, dan sebagainya. Desain komunikasi visual yang baik membantu mengkomunikasikan pengelompokan (grouping). Lewat prinsip-prinsip desain komunikasi visual sistem organisasi dapat dengan mudah dimengerti dan memudahkan khalayak dalam menggunakan sistem. Sistem pelabelan merupakan sistem penamaan dari sebuah modul desain. Dalam konteks website bisa berupa penamaan pada headline halaman-halaman, juga bisa juga pengkategorian untuk search engine optimization. Dengan mengetahui kebutuhan dan keinginan khalayak yang dituju, sistem pelabelan harus disusun berdasarkan hirarki kebutuhan klien.

Sistem Navigasi harus disusun dari navigasi global (global navigation system atau navigasi untuk keseluruh sistem), navigasi lokal (navigasi dalam halaman yang sama), hingga navigasi kontekstual (yaitu navigasi dalam konteks atau bagian tertentu di dalam sebuah halaman). Prinsip desain seperti arah, gerak, keseimbangan, harus direncanakan secara tepat dalam mendukung proses navigasi. 


\section{Prinsip UX dalam Brand}

Dalam memberikan pengalaman brand kepada khalayaknya, setiap brand sebaiknya mempunyai kaidah-kaidah atau pedoman yang ditetapkan dalam memberikan pengalaman tertentu kepada khalayaknya. Kaidah ini harus berangkat dari insightkhalayaknya sendiri. Kaidah ini harus dijaga dari waktu ke waktu, dan diterjemahkan ke dalam setiap kegiatan dan komunikasi Brand di dalam setiap titik sentuh (touch point) kepada khalayaknya, termasuk di dalamnya desain komunikasi visual.

Contoh kaidah UX yang dipegang oleh Google (n.d.), yaitu fokus kepada khalayak-hidup mereka, pekerjaan mereka, dan mimpi mereka; (2) setiap mili-detik haruslah diperhitungkan; (3) kesederhanaan adalah kekuatan; (4) libatkan pemula dan pikat para ahli; (5) berani untuk berinovasi; (6) desain untuk dunia; (7) rencanakan untuk bisnis hari ini dan esok hari; (8) senangkan mata tanpa mengganggu pikiran; (9) menjadi layak untuk kepercayaan masyarakat; (10) tambahkan sentuhan manusia.

\section{PENUTUP}

Dalam tulisan ini hanya dibahas konsep dasar user experience dalam hubungannya dengan desain komunikasi visual. Konsep UX memiliki dimensi yang begitu luas, baik dari sisi psikologis, sisi pemikiran, sisi fisiologis, budaya, sampai teknis dan eksekusi seperti programing dsb yang belum disentuh dalam tulisan ini. Desain sebagai garda depan dalam user interface kini dituntut lebih menjiwai proses pembentukannya lewat bidang-bidang tadi. Untuk itu penelitian lebih lanjut terhadap proses pembelajaran UX yang terintegrasi dan efisien sangatlah diperlukan.

\section{DAFTAR PUSTAKA}

Google. (n.d.). Google user Experience. Diakses pada 30 Juli 2011, dari http://www.google.com/about/corporate/company/ux.html

International Organization for Standardization (ISO) Switzerland. SO FDIS 9241-210.[2009]. Ergonomics of human system interaction - Part 210: Human-centered design for interactive systems (formerly known as 13407)

King, D. L. (2008). Designing the digital experience: How to use experience design tools and techniques to build websites customers love. New Jersey: Cyber Age Books.

Lidwell, W., Holden, K., \& Butler, J. (2003). Universal principles of design. Massachussets, US: Rockport Publisher.

Lindstorm, M. (2008). Buyology: Truth and lies about why we buy. New York: Crown Publishing.

Mullins, P. M., \& Treu, S. (1991). Measurement of stress to gauge usersatisfaction with features of the computer interface. Behaviour\& Information Technology ,10 (4), 325-343.

Schleifer, L. M., \& Geoffrey, O. O. (1990). System response time and method of pay: Cardiovascular stress effects in computer-based tasks. Ergonomics, Vol 22(12), Dec 1990, 1495-1509. 
Wastell, D. (1990). Mental effort and task performance: Towards a psycho physiology of human computer interaction. In Proceedings of the IFIP INTERACT '90 third international conference on human-computer interaction, Cambridge, UK, 27-31 August, 107-112.

Wilson, C. (2010). User experience re-mastered. your guide to getting the right design. Michigan, US: Morgan Kaufmann.

\section{RIWAYAT PENULIS}

Mendiola B Wiryawan lahir di kota Jakarta pada 22 Januari 1977. Penulis menamatkan pendidikan S1 di Universitas Pelita Harapan dalam bidang Desain Komunikasi Visual pada 2000. Saat ini bekerja sebagai dosen di Universitas Bina Nusantara. Penulis aktif di Asosiasi Desain Grafis Indonesia sebagai Director of Brand and Communication. 